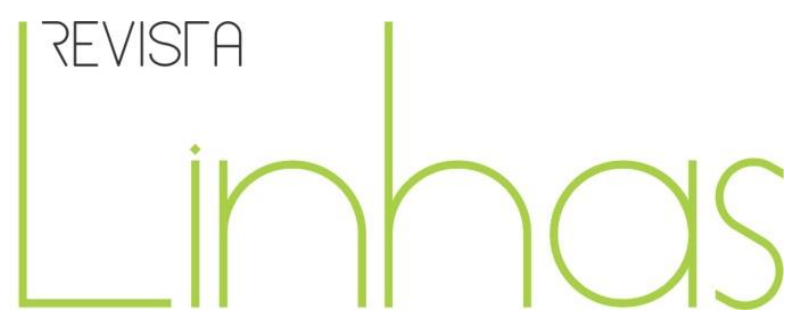

\title{
Itinerários do Aluno Felte Bezerra entre Sergipe e Bahia na primeira metade do século $X X^{1}$
}

\begin{abstract}
Resumo
Este texto tem como objetivo analisar os itinerários escolar e acadêmico de Felte Bezerra (1908-1990), um intelectual nascido em Sergipe, estado em que se concentrou a maior parte da sua vida e da sua vasta produção intelectual. Felte cursou o ensino secundário no Colégio Tobias Barreto em Sergipe e, logo depois, estudou Odontologia na Escola Anexa da Faculdade de Medicina na Bahia. Os registros das suas vivências estudantis foram vasculhados em diferentes arquivos privados e públicos, além das memórias registradas por ele em seus últimos anos de vida e entrevistas com familiares e ex-alunos. Os fundamentos teórico-metodológicos que embasam este estudo atendem aos conceitos de intelectual, itinerários e estruturas de sociabilidade compostas por redes e microclimas do autor francês Jean-François Sirinelli. Os seus percursos escolares desvelaram instituições educacionais, docentes, disciplinas e seus conteúdos, elementos cruciais para o entendimento da História da Educação Brasileira.
\end{abstract}

Palavras-chave: Bezerra, Felte, 1909-1990. Educação - Sergipe História. Intelectuais - Sergipe.

\footnotetext{
João Paulo Gama Oliveira

Universidade Federal de Sergipe

- UFSE - Aracaju/SE - Brasil

profjoaopaulogama@gmail.com

Eva Maria Siqueira Alves

Universidade Federal de Sergipe

- UFSE - Aracaju/SE - Brasil evasa@uol.com.br
}

\begin{abstract}
Para citar este artigo:
OLIVEIRA, João Paulo Gama; ALVES, Eva Maria Siqueira. Itinerários do Aluno Felte Bezerra entre Sergipe e Bahia na primeira metade do século XX. Revista Linhas. Florianópolis, v. 19, n. 39, p. 216-242, jan./abr. 2018.
\end{abstract}

DOI: $10.5965 / 1984723819392018216$

http://dx.doi.org/10.5965/1984723819392018216

\footnotetext{
${ }^{1} \mathrm{O}$ presente artigo constitui-se como um desdobramento da tese: "Caminhos cruzados: itinerários de pioneiros professores do ensino superior em Sergipe (1915-1954)" defendida no Programa de PósGraduação em Educação da Universidade Federal de Sergipe. Para outras informações ler Oliveira (2015).
} 


\title{
Itineraries of the student Felte Bezerra between Sergipe and Bahia in the first half of the 2oth Century
}

\begin{abstract}
This text aims to analyze the scholar and academic itinerary of Felte Bezerra (1908-1990), an intellectual that was born in Sergipe, State in which he concentrated the biggest part of his life and of his wide intellectual production. Felte attended high school at the Tobias Barreto School in Sergipe and soon after studied Odontology at a school linked to the Medicine College in Bahia. The records of his student life experiences, besides the memories registered by himself in his last years of life were searched in different private and public files; also interviews with family and former students were taken into account. The theoretical and methodological foundations that support this study attend to concepts of the French author Jean-François Sirinelli, such as "intellectual", "itineraries" and "sociability structures composed by networks and microclimates". His scholar trajectories unveil educational institutions, teaching staff, subject areas and his contents, crucial elements for the understanding of the Brazilian Education History.
\end{abstract}

Keywords: Bezerra, Felte, 1909-1990. Educational Sergipe - History. Intellectuals - Sergipe. 


\section{Felte Bezerra, uma breve apresentação}

Felte Bezerra (1908-1990) ${ }^{2}$ constitui-se como um intelectual nascido em Sergipe, estado que concentrou a maior parte da sua vida, como também da sua vasta produção intelectual. Residiu em Salvador/BA, local em que cursou a graduação em Odontologia na Faculdade de Medicina da Bahia (1930-1933); retornou a Aracaju/SE, onde seguiu os caminhos do Magistério e participou de diferentes "estruturas de sociabilidade" (SIRINELLI, 1988) por mais de três décadas. Após 1959, migrou para o Rio de Janeiro, ali permanecendo até o final da sua vida.

Entre as décadas de 1930 e 1950, Felte Bezerra publicou livros, participou de congressos em diferentes lugares do mundo, escreveu para a imprensa local acerca de diversas temáticas, envolveu-se em polêmicas com seus opositores, realizou pesquisas científicas, só para citar algumas das ocupações que permearam os “itinerários" desse intelectual.

Além disso, cabe destacar que ele ocupou a Presidência do Instituto Histórico e Geográfico de Sergipe, manteve correspondência ativa com os renomados pesquisadores da área de Antropologia no Brasil, como mostraram Dantas e Nunes (2009); fez parte da Academia Sergipana de Letras, entre outras confrarias e, sobretudo, buscou inserir-se nas "redes" e "microclimas" que estruturavam a "sociabilidade" da intelectualidade sergipana de outrora (SIRINELLI, 1986, 1988, 2003).

No âmbito do magistério, fez parte da Congregação do Atheneu Sergipense ${ }^{3}$, primeiro como Professor interino de Inglês, depois como Catedrático de Geografia, chegando até a direção daquela renomada escola de Ensino Secundário. Foi também um dos pioneiros na fundação do Ensino Superior em Sergipe, na função de catedrático de Antropologia na Faculdade Católica de Filosofia de Sergipe, instituição criada em 1951.

Diante da diversidade de fatos que envolvem sua vida, o presente artigo objetiva analisar os itinerários escolar e acadêmico de Felte Bezerra (1908-1990). Assim, os investigamos antes da consolidação como intelectual e, dessa forma, lançamos o olhar

\footnotetext{
${ }^{2}$ Sobre Felte Bezerra há uma série de trabalhos com distintos focos, para saber mais ler Oliveira (2015).

3 Segundo Alves (2005), ao longo dos anos, o Atheneu Sergipense recebeu variadas denominações; nesse trabalho, utilizamos a nomenclatura Atheneu Sergipense para facilitar o entendimento do leitor. A respeito dos diferentes traços da história dessa "Casa de Educação Literária”, ver Alves (2005).
} 
para analisar sua constituição como aluno do Colégio Tobias Barreto, em Sergipe, e como acadêmico do curso de Odontologia, na Faculdade de Medicina da Bahia.

O estudo dos "itinerários" ocorreu através da análise das origens do seu despertar intelectual nas instituições educacionais que frequentou e dos mestres que foram registrados nos escritos de Felte Bezerra. De acordo com o que escreveu Jean-François Sirinelli (2003):

[...] em todo caso, é possível e necessário fazer sua arqueologia [das estruturas de sociabilidade], inventariando as solidariedades de origem, por exemplo de idade ou de estudos, que constituem muitas vezes a base de 'redes' de intelectuais adultos. É lógico, sobretudo no caso dos acadêmicos, remontar a seus jovens anos escolares e universitários, numa idade em que as influências se exercem sobre um terreno móvel e em que uma abordagem retrospectiva permite reencontrar as origens do despertar intelectual e político. (SIRINELLI, 2003, p. 249-250, grifos nossos)

A proposta não consiste em fazer uma genealogia, como adverte Sirinelli, mas uma arqueologia, na qual investigamos como a vivência estudantil e os seus professores, colegas e escolas, contribuíram para conformar sua condição de intelectual. JeanFrançois Sirinelli $(1998,2003,2006)$ ensina que a história dos intelectuais não é uma história autônoma, nem fechada sobre si, pelo contrário, é aberta e localizada no cruzamento das histórias política, social e cultural. Para o referido autor, o intelectual precisa ser estudado a partir da sua atuação tanto no âmbito político como cultural ou da produção do conhecimento. O teórico francês acentua que o meio intelectual constitui "um pequeno mundo estreito", no qual, "os laços se atam" em torno da redação de uma revista ou de um conselho editorial (SIRINELLI, 2003, p. 248).

Entendemos que as instituições educacionais também se configuram como um lugar no qual "os laços se atam" a depender da "sensibilidade ideológica ou cultural comum e de afinidades mais difusas". Diante disso, a análise dos itinerários permite visualizar como tais laços se conformaram ao longo do tempo e os espaços frequentados por esse jovem estudante nas primeiras décadas do século XX. 
O conceito de "itinerário" advém do mesmo autor, o qual trata dos "itinerários políticos" como aqueles que "[...] deveriam permitir desenhar mapas mais precisos dos grandes eixos de engajamento dos intelectuais" (SIRINELLI, 2003, p. 245). Utilizamos o conceito de itinerários de acordo com o seguinte entendimento dos "itinéraires":

Ces itinéraires individuels ou collectifs devraient donc permettre, par superposition, de faire apparaître les parcours types de l'engagement et aussi, en arrêtant le déroulement chronologique à une époque donnée, d'établir de véritables coupes datées de la societé intellectuelle. A travers deux dimensinons, seraient ainsi facilités le passage du portulan à la carte et celui de la radiographie au scanner, et disparaîtraient peu à peu les terrae incongnitae qui recouvrent encore largement, pour l'instant, les atlas dont l'historien dispose l'étude des intellectuels. ${ }^{4}$ (SIRINELLI, 1986, p. 102)

A investigação dos itinerários de Felte Bezerra possibilita compreender o percurso de um jovem brasileiro em seu processo de escolarização na primeira metade do século XX. Assim, as "terras desconhecidas", no tocante à história desse intelectual sergipano, são desbravadas de forma que explicitamos o modo como, por meio dos itinerários, pode-se compreender a mudança do "portulano ao mapa" da mesma forma que "da radiografia ao scanner" no trato com os "criadores" e "mediadores culturais" (SIRINELLI, 2003).

Para o teórico francês, os "intelectuais" são: "[...] criadores e 'mediadores' culturais [...] estão abrangidos tanto o jornalista como o escritor, o professor secundário como o erudito [...]" (SIRINELLI, 2003, p. 242). Em outra obra, o autor explica mais minuciosamente seu entendimento acerca dos “criadores" e dos "mediadores culturais": “[...] à primeira categoria pertencem os que participam da criação artística e literária ou no progresso do saber, na segunda juntam-se os que contribuem para difundir e vulgarizar os conhecimentos dessa criação e desse saber" (SIRINELLI, 1998, p. 261).

\footnotetext{
${ }^{4}$ Tradução livre: "Estes itinerários individuais ou coletivos devem, portanto, permitir, por sobreposição, mostrar os tipos de percursos de engajamento e também, convencionando a sequência cronológica de um determinado momento ao estabelecer verdadeiros recortes de uma dada sociedade intelectual. Através de duas dimensões seria assim facilitada a passagem do portulano ao mapa, e da radiografia ao scanner, e desapareceriam pouco a pouco as terrae incongnitae (terras desconhecidas) que recobrem ainda amplamente, por enquanto, os atlas cujo historiador dispõe o estudo dos intelectuais" (SIRINELLI, 1985, p. 102).
} 
Ainda com relação à mediação cultural, o autor esclarece que: "As elites de mediação cultural poderiam ser, com efeito, entendidas como dotados de certa capacidade de ressonância e de amplificação, noutros termos de um poder de influência" (SIRINELLI, 1998, p. 261). Desse modo, faz-se necessário problematizar os itinerários da vida desse sujeito, não como agente inerte situado em um tempo e um espaço e movido pelas circunstâncias de sua época, mas como um ser com anseios, medos e expectativas que, diante de escolhas efetuadas ao longo de diferentes momentos de sua vida, construiu paulatinamente uma história, dentro de uma série de opções ou não, que se apresentavam naquele momento, sendo um indivíduo que fez parte de grupos de "elites de mediação cultural" entre Sergipe e Bahia na primeira metade do século XX.

\section{Felte Bezerra e sua infância entre "o aroma das rôxas flores de cajueiros"}

Felte Bezerra nasceu em Aracaju, no ano de 1908 e faleceu na cidade do Rio de Janeiro em 1990. Era filho de Abdias Bezerra e Esmeralda Araújo. Seu pai era professor e nasceu na cidade de Siriri, no interior do estado de Sergipe, no ano de 1880 , filho do professor João Amâncio Bezerra e D. Herminia Rosa Bezerra.

Abdias Bezerra ficou viúvo muito cedo, desse modo, a educação dos seus filhos, Felte e Floro Bezerra, ficou sob a sua responsabilidade. Casou-se pela segunda vez, sendo pai de mais três filhos. Seu pai consagrou-se como um professor ativo e ligado à política sergipana. Conforme sua filha, Suzana Bezerra, Felte:

Foi criado por uma tia paterna, irmã de Abdias Bezerra de nome Euridices Bezerra, que morava juntamente com seu pai, na mesma casa, na Rua de Arauá, se não me engano $n^{\circ} 330$ ou 333 , pois perdera a mãe de parto quando tinha, apenas, 6 anos de idade e o irmão Floro com 4 anos. A mãe de quem não guardava lembranças por tê-la perdido muito cedo chamava-se Esmeralda Bezerra. O pai casara após 6 meses de viúvo, daí a tia ter feito o papel de sua mãe em razão de sua madrasta Lola Bastos Bezerra ter tido 3 filhas mulheres. Ela se sentiu na obrigação em defesa dos sobrinhos órfãos e fez o papel de mãe. (BEZERRA, 2015, s/p)

Nas suas próprias palavras, em um texto que trata das memórias de sua vida ou dos “escritos de si”, Felte Bezerra (1988) relata: "Perdi minha mãe, aos seis anos de 
idade. Contudo, não fiquei desamparado e só, como um joguete em mãos trêfegas. Tive um pai a quem devo a formação de meu caráter, auxiliado pela mão feminina de minha tia paterna Euridice". Em outro trecho, trata da pobreza do seu pai e da sua segunda família:

Meu pai sempre foi muito pobre, probo, altamente respeitado, mas sem recursos para manter-me fora para estudar. Foi um simples professor de Província e vivia de seus minguados ganhos, atingindo a paternidade de cinco filhos: meu irmão Floro, do primeiro matrimônio, e minhas irmãs Maria, Dulce e Hermínia, filhas de minha madrasta. (BEZERRA, 1988, p. 2)

Assim, Felte viveu seu período de infância, nas primeiras décadas do século XX, ao lado de seus irmãos, do pai, da madrasta, pouco citada em seus depoimentos, e da sua tia, a quem atribui a sua educação juntamente com o pai. Contudo, é necessário explicitar que o salário de catedrático de seu genitor, como também os cargos que exerceu, não permitem classificá-lo como alguém de extrema pobreza econômica. Como lembra Gontijo:

Por meio de um exercício marcado por lembranças e esquecimentos constrói-se um conjunto de representações compartilhadas, capazes de atribuir significado positivo ou negativo a períodos, personagens, acontecimentos, obras, narrativas sobre o presente, o passado e 0 futuro. (GONTIJO, 2007, p. 311)

Nas lembranças de Felte, ele demarca a posição de seu pai e sua presença na sua escolarização, bem como os investimentos realizados para sua formação. Acontecimentos marcados na sua memória e que se fizeram presentes em seus escritos já em seus últimos anos de vida. Ali, Felte Bezerra também registrou aspectos dos seus primeiros passos.

Sobre a infância de Felte, na cidade de Aracaju, no início de 1900, as recordações de Mário Cabral (1951) ajudam a vislumbrar aspectos de uma capital na fase anterior ao bonde, ao cinema e ao asfalto. Ao descrever suas memórias, o autor relembra que as crianças nas ruas arenosas brincavam de calçadinha do rei, de cipozinho queimado ou, em noite de plenilúnio, de roda, de berlinda ou cabra-cega. 
Segundo Cabral, era nítida a distinção entre as brincadeiras de meninas e meninos - enquanto elas brincavam de roda ou de pinta galo, tendo por limite a calçada ou a rua, eles iam mais longe, desbravando não só as ruas, mas os terrenos baldios próprios para as brincadeiras como da manja. Entre as formas de escolhas diretas e seleção nas brincadeiras de Aracaju de outrora, relembra algumas, entre elas a seguinte:

\author{
Uma pulga na balança \\ deu um pulo \\ foi à França \\ os cavalos a correr \\ os meninos a brincar \\ vamos ver \\ quem vai \\ pegar (CABRAL, 1951, p. 185)
}

E assim transcorria a infância daqueles meninos e meninas que povoavam a capital de Sergipe; entre eles, estava Felte Bezerra. Conforme Dantas (2004), nos primeiros decênios de 1900, Sergipe viveu um período de modernização, a economia diversificouse, as indústrias têxteis se propagaram, inclusive, aumentando o número de empregos. Houve a instalação de água encanada e de luz elétrica, os bondes à tração animal e os carros elétricos, a primeira estrada de rodagem, telefone, mercado, entre outras tantas inovações.

Loureiro (1983) explana sobre algumas mudanças na capital sergipana como: a inauguração da rede de esgoto e destaca a ocupação dos espaços centrais e uma estratificação sócio-espacial entre o norte e o sul da cidade. Ao norte, a cidade atingia o bairro Chica Chaves, atual bairro Industrial, onde residiam as pessoas de menor poder aquisitivo; e ao sul, chegava-se à Fundição, no extremo da Rua da Aurora. Na região central da capital, morou Felte Bezerra. Epifânio Dórea forneceu outra visão sobre o início do século XX na Capital de Sergipe:

Quando nos fixamos nesta Capital, em maio de 1907, já não era possível saborear-se com a facilidade de outrora, os cambuís, cambucás e gragerus dos arredores aracajuano, já sacrificados pelo simplismo e imprevidência do povo. 
Todavia, ainda encontramos, embora em escala mínima, o aroma das rôxas flores de cajueiros, essa dádiva do céu que é a ganância humana procura fruir o mais que pôde, não zelando-a porém.

Havia donos de sítios, que propiciavam aos seus visitantes, nas épocas próprias, prazeirosamente, a gustação de saborosos cajús.

E que lindos que eles eram! (DÓREA, 1954, p. 109/110)

Foi nesse cenário de mudanças e transformações, com "o aroma das rôxas flores de cajueiros" dos "saborosos cajús" da Capital de Sergipe que cresceu Felte Bezerra, ao lado de sua família e, já na fase da adolescência, é descrito por Garcia Moreno da seguinte forma: “[...] daquele meúdo adolescente de 1924, ainda sem buço, de olhos vivos e rosto avermelhado de espinha, talvez com as suas primeiras calças compridas, sentindo que era o último preparatório prestado, aos 15 anos de idade [...]" (MORENO, 1952, p. 3).

Felte pertencia a uma família de professores, seu avô paterno João Amâncio Bezerra lecionava em Siriri, cidade do interior do estado e o, pai Abdias Bezerra, passou uma infância difícil trabalhando em diversos ofícios, mas, após o retorno do Rio de Janeiro, sua vida foi dedicada ao Magistério e a outras funções relacionadas à Educação. A figura do seu pai, o professor Abdias Bezerra, é marcada pela cátedra no Atheneu Sergipense e pelos cargos públicos assumidos ao longo da vida, aspectos que, provavelmente, contribuíram para a ida de Felte Bezerra à Bahia, a fim de cursar o Ensino Superior, bem como para o seu retorno a Aracaju, acompanhado pelo automático ingresso como Professor interino no Atheneu Sergipense, em 1935. Antes disso o seu processo de escolarização ocorreu no Colégio Tobias Barreto, na capital de Sergipe.

\section{Itinerários do aluno Felte Bezerra no colégio Tobias Barreto: professores que marcaram suas memórias}

Além de meu pai, cujas pegadas sempre em meu caráter e que foi meu professor secundário. Devo muito a outro professor, Alcebíades Correia Paes, cujo lar frequentei em minha adolescência [...]. Abdias meu pai, e Alcebíades, [...], foram mestres de tudo, mas, sobretudo de caráter. Ambos eram capazes de lecionar qualquer disciplina. Complementarmente, devo mencionar um terceiro professor, Arthur Fortes, que também influiu com seus exemplos em minha formação. Abdias ensinou-me um ano de francês, matemática, desenho geométrico, física e química. Alcebíades ensinou-me um ano de francês, inglês, 
português, geografia e biologia. Fortes um ano de francês, história geral e história do brasil. Devo assinalar que ainda estudei inglês (um ano) com Manuel Franco Freire e Latim com José Augusto da Rocha Lima. (BEZERRA, 1988, p. 2)

A partir dos escritos de Felte Bezerra, investigamos quem são esses professores que deixaram marcas em suas memórias e concomitantemente, abordamos elementos da História da Educação em Sergipe por meio dos seus itinerários como aluno no Colégio Tobias Barreto em Aracaju. No texto escrito, quase meio século depois do vivido, Felte lembra o fato de frequentar a casa de Alcebíades Paes, dos pais serem amigos e da contribuição dos mestres na formação do seu caráter para além dos conhecimentos escolares ensinados.

Felte Bezerra refere-se a Alcebíades de maneira igualitária ao seu pai como "mestres de tudo", possivelmente tal denominação não está vinculada somente ao conhecimento que permitia aos dois docentes lecionarem várias áreas do saber, mas, sobretudo às contribuições fornecidas à formação pessoal do jovem Felte.

Na capital de Sergipe, os antigos colegas da Escola Militar da Praia Vermelha, Abdias Bezerra juntamente com Arthur Fortes, foram os primeiros a lecionarem no Colégio Tobias Barreto, assim como fizeram parte da Congregação do Atheneu Sergipense. Segundo o Dicionário de Armindo Guaraná (1925), o professor Arthur Fortes 5 foi nomeado Professor vitalício da cadeira de História do Brasil e Geral do Atheneu Sergipense, por decreto de Oliveira Valadão, em 1916; já Abdias Bezerra ingressou por meio de concurso nessa mesma instituição, em 1909.

Ao lado de Fortes e Bezerra, o Professor Alcebíades Paes é citado por Felte Bezerra como um dos professores que mais contribuíram em seu processo formativo. Alcebíades também foi Professor do Atheneu Sergipense, tendo ali ingressado em 1909 como professor de Inglês sendo graduado em Medicina (ALVES, 2005). Já o Professor José Augusto da Rocha Lima, foi um dos sergipanos que viajaram para outros estados do país para conhecer os métodos da Escola Nova.

\footnotetext{
5 Segundo Guaraná (1925), Arthur Fortes, nasceu em 23 de julho de 1881 em Aracaju, filho de Antonio Augusto Gentil Fortes e Antonia Junqueira Fortes. Fez o Curso de Humanidades com o professor Alfredo Montes e no Atheneu Sergipense. Além do próprio Atheneu, foi professor do Colégio Tobias Barreto de História e Francês e, no Instituto América, lecionou Francês e Geografia.
} 
Rocha Lima era docente da Escola Normal Rui Barbosa, do Atheneu Sergipense e do Colégio Tobias Barreto, além de inspetor da Instrução Pública, atuando de forma dinâmica nos diferentes espaços educativos de Sergipe na primeira metade do século XX. Barroso (2011) considera que a viagem de Rocha Lima a São Paulo a fim de conhecer as inovações pedagógicas ocorridas lá, sendo recepcionado por Lourenço Filho, além da sua possível aplicação em Sergipe e da publicação do relatório acerca da mesma, aumentaram o nível de influência do Professor no campo educacional sergipano. Para a autora, Rocha Lima criou laços com outros intelectuais da educação que defendiam a modernização pedagógica e metodológica para o Ensino Primário e Normal nas primeiras décadas do século XX.

Barroso (2011) também situa o professor Manoel Franco Freire, exposto nas memórias de Felte Bezerra, ao lado de Augusto da Rocha Lima, Helvécio de Andrade, Rodrigues Dórea, Carlos Silveira e Graccho Cardoso como sujeitos interligados nas tentativas de impor suas concepções de modernização pedagógica em Sergipe. Franco Freire foi Diretor da Escola Normal Rui Barbosa e da Instrução Pública, no final da década de 1920, além de ter exercido a docência de Geometria no Atheneu Sergipense e de Inglês na Escola de Comércio Conselheiro Orlando e no Colégio Tobias Barreto, configurando-se também como um entusiasta pelos princípios da Pedagogia Moderna.

Ainda segundo a referida pesquisadora, Franco Freire, assim como Abdias Bezerra, Rocha Lima, entre outros, não só atuaram como Professores, Diretores e Inspetores da Instrução Pública, como também compuseram o conjunto de técnicos que viajaram para outros estados a fim de observar o sistema educativo "renovado" com o intuito de implantar em Sergipe.

As aulas que Felte Bezerra recebeu com esses professores ocorreram no Colégio Tobias Barreto, no centro de Aracaju. Segundo Mangueira (2003), o Colégio Tobias Barreto foi criado em 9 de maio de 1909, na cidade de Estância/SE, por José de Alencar Cardoso, com o estímulo do seu pai, o professor Severiano Cardoso ${ }^{6}$, como também do professor e seu tio, Brício Cardoso. O Colégio foi transferido, quatro anos depois para a cidade de Aracaju. Consoante o autor: “[...] a criação do Colégio Tobias Barreto

\footnotetext{
${ }^{6}$ Sobre Severiano Cardoso, Armindo Guaraná (1925) afirma que nasceu em 1840 na cidade de Estância e faleceu em outubro de 1907, em Aracaju. Foi professor da Escola Normal, do Atheneu Sergipense, bem como do Parthenon Mineiro em Minas Gerais e do Parthenon Sergipano de Ascendino dos Reis.
} 
apresenta-se com o objetivo político de formar novos quadros para o grupo dos militares, bem como viabilizar através da educação um caminho de compreensão do novo mundo: urbano-industrial, que aparecia para Sergipe" (MANGUEIRA, 2003, p. 31).

Ainda sobre o período de estudos nessa instituição, Felte escreveu acerca do seu Diretor e Professor Primário: “Meu estudo secundário, o fiz, [...], no então famoso colégio Tobias Barreto, no curso primário tive único decurião, pedagogo. O diretor deste, [...] colégio, José Alencar Cardoso, o professor Zezinho, como era chamado. Excelente pedagogo que mais tarde foi concunhado de meu pai [...]" (BEZERRA, 1981a, p. 3). As memórias de Felte apontam para o nome daquele que foi seu primeiro docente, Professor Zezinho, o mesmo que atuou junto com seu pai na Revolta do Rio de Janeiro.

Vale mencionar as assertivas de Bontempi Júnior (2010, p. 176) acerca da evocação das memórias no tocante aos docentes em um estudo específico dos memoriais dos candidatos da Faculdade de Educação da Universidade de São Paulo, mas que dialogam com o presente texto: “[...] na carreira de professor, carregada de sentido missionário e ascético, parece ser preferível dar a entender que a escolha tenha-se dado em um passado do qual teria emergido essa vocação a dizer que haja, a vislumbrar no futuro, benefícios a obter posse do cargo". Nos escritos de Felte Bezerra datados de 1988, o Professor aposentado busca "[...] dar a entender que a escolha tenha-se dado em um passado do qual teria emergido essa vocação".

Na perspectiva de conhecer mais acerca do Diretor daquele estabelecimento de ensino, localizamos nas memórias do ex-estudante Joel Silveira o regime disciplinar do Diretor, quando Silveira descreve o que lhe aconteceu ao ter descumprido as regras daquele Colégio: “E fui logo correndo para a porta da saída, antes que o professor Benedito, subdiretor do colégio, surgisse com a sua ameaçadora e impiedosa vara de bambu, da qual usava e abusava com grande maestria" (SILVEIRA, 1998, p. 22).

O caráter disciplinador permeava a instituição que também funcionava como internato. Contudo, as memórias de Felte Bezerra não fazem menção às regras, disciplina e mesmo aos castigos existentes na busca pela manutenção da ordem naquela escola. Felte Bezerra optou por registrar os nomes dos Docentes, as marcas deixadas no seu processo formativo e, dessa maneira, sua memória selecionou os acontecimentos e os sujeitos que deveriam ficar marcados na sua história. Entre os sujeitos, estava Arthur 
Fortes. Acerca dos ensinamentos desse Professor, Felte escreveu um artigo em virtude do centenário de nascimento do "Poeta das Rosas Vermelhas" e de suas aulas no Colégio Tobias Barreto, destacando:

Com Artur Fortes iniciamos o conhecimento da língua francesa, mas muito especialmente a História do Brasil e do Mundo, em magistrais preleções, encantadoras pelo conteúdo, a segurança e a beleza de estilo com que eram proferidas. Ao termino de cada uma delas sempre sentíamos uma ponta de desapontamento, porque a aula acabara ... Restava-nos aguardar a próxima com o mesmo anseio e o mesmo entusiasmo com que nos contagiava o mestre. É grande o débito dos da nossa geração para com o nomeado historiador.

Era bom vê-lo expressar-se em linguagem poética, mansa ou exacerbada, motejadora ou economiástica, ao sabor das circunstâncias transmitindonos as cenas e os episódios que nos descrevia, ao conseguir o milagre de nos tornar virtuais partícipes do que era relatado, tal a nitidez com que vivia o que expunha.

Palavra fácil, clara, vibrátil repassada às vezes de VERVE e de um tom especial daquela FINESSE do espírito francês, traindo a ascendência do notável CAUSEUR. (BEZERRA, 1981a, p. 3)

O texto escrito aproximadamente sessenta anos depois daquelas aulas e em razão do centenário do antigo mestre, coaduna-se com o que ensina Pesavento:

Aquele que lembra não é mais o que viveu. No seu relato, há reflexão, julgamento, ressignificação do fato rememorado. Ele incorpora não só o relembrado no plano da memória pessoal, mas também o que foi preservado ao nível de uma memória social partilhada, ressignificada, fruto de uma sanção e de um trabalho coletivo. Ou seja, a memória individual se mescla com a presença da memória social, pois aquele que lembra rememora em um contexto dado, já marcado por um jogo de lembrar e esquecer. (PESAVENTO, 2005, p. 94)

Nesse “jogo de lembrar e esquecer”, Felte Bezerra registrou nas suas memórias alguns dos seus docentes como "mestres de tudo". Dos Professores mencionados, dois tiveram sua formação na Escola da Praia Vermelha - Arthur Fortes e Abdias Bezerra. Conforme José Murilo de Carvalho (2010), naquela escola havia uma formação ampla no âmbito cultural, intelectual, político e social. A primeira, desenvolvida em atividades 
extracurriculares como sociedades, clubes e revistas literárias, além das matérias centradas nas Matemáticas, Engenharias e Ciências da Natureza.

No plano intelectual, contava-se com as correntes de pensamento europeias, principalmente, o Positivismo de Auguste Comte e o Evolucionismo de Charles Darwin e Herbert Spencer. No viés político, o autor cita o fato de a Escola estar envolvida diretamente com a Abolição e a Proclamação da República no Brasil. Por fim, a dimensão social na qual "[...] a Escola Militar da Praia Vermelha, não formava soldados, formava bacharéis fardados" (CARVALHO, 2010, p. 145).

Foi com elementos dessa formação que Abdias Bezerra, pai de Felte, e Arthur Fortes deixaram a capital do país e voltaram para Sergipe, ingressando na política e no universo da educação como catedráticos no Atheneu Sergipense e professores de renomados colégios particulares como o Colégio Tobias Barreto, instituição na qual lecionaram a Felte Bezerra. Do ensino no Tobias Barreto, ficaram as marcas dos "mestres de tudo".

Com esses e outros professores como Brício Cardoso e o próprio Alencar Cardoso, também Diretor do estabelecimento de ensino, Felte Bezerra estudou de 1915 até 1924. Mangueira (2003) afirma que entre 1913 e 1924, o horário de funcionamento da instituição estava dividido em duas sessões - a primeira das gh às $13 \mathrm{~h}$; e a segunda das $15 \mathrm{~h}$ às $17 \mathrm{~h}$ - o que o caracterizava como um Colégio em tempo integral. Conforme a Reforma Carlos Maximiliano (BRASIL, 1915):

Art. 167. A distribuição das materias, no curso official de qualquer das secções do Collegio Pedro II, será a seguinte:

$1^{\circ}$ anno - Portuguez, Francez, Latim e Geopraphia Geral.

$2^{\circ}$ anno - Portuguez, Francez, Latim, Arithmetica, Chorographia do Brazil e noções de Cosmographia.

$3^{\circ}$ anno - Portuguez, Francez, Inglez ou Allemão, Latim, Algebra e Geometria plana.

$4^{\circ}$ anno - Inglez ou Allemão, Historia Universal, Geometria no espaço, Trigonometria rectilinea, Physica e Chimica.

$5^{\circ}$ anno - Inglez ou Allemão, Physica e Chimica, Historia do Brazil e Historia Natural.

Paragraphounico. Haverá licções de Gymnastica e Desenho nos quatro primeiros anos. (BRASIl, 1915) 
Contrapondo o texto da Reforma de 1915 ao trabalho de Mangueira (2003), o autor identifica as disciplinas ali lecionadas no citado período, sendo: História Universal, História do Brasil, História Natural, Geometria, Álgebra, Física, Química, Geografia, Português, Alemão, Francês e Latim. Além dos livros utilizados como os de Aritmética, de Antônio Trajano, Geografia, de Lacerda, Gramática, de Eduardo Carlos Pereira, História do Brasil, de João Ribeiro e a Antologia, de Fausto Barreto. Com esses compêndios e muitos outros, possivelmente, Felte Bezerra estudou naquela instituição educacional.

Por meio dos escritos de Felte, da legislação e da relação de disciplinas elaborada por Mangueira, foi possível construir o seguinte quadro:

Quadro 1 - Itinerários da formação educacional de Felte Bezerra no Colégio Tobias Barreto

\begin{tabular}{|l|l|}
\hline CADEIRAS & PROFESSORES \\
\hline História Universal & Artur Fortes \\
História do Brasil & Artur Fortes \\
História Natural & Alcebíades Paes \\
Álgebra & Abdias Bezerra \\
Física & Abdias Bezerra \\
Química & Abdias Bezerra \\
\hline Geografia & Abdias Bezerra \\
Português & Alcebíades Paes \\
\hline Alemão & Alcebíades Paes \\
Latim & José Augusto da Rocha Lima \\
Francês & Abdias Bezerra \\
& Alcebíades Paes \\
Inglês & Artur Fortes \\
\hline
\end{tabular}

Fonte: Quadro extraído de Oliveira (2015).

As disciplinas e os professores com os quais estudou Felte Bezerra fornecem elementos para entender seu itinerário formativo, aspectos da sua vida de estudante, introduzido em um colégio cujo sobrenome já ecoava de forma diferenciada, tendo em vista o vínculo do pai com a instituição, além da influência paterna nos direcionamento da educação sergipana. Felte estava inserido em um sistema de ensino que contribuiu para a 
sua formação pessoal e profissional, marcas de um percurso que se fizeram sentir mesmo tempos depois, como assevera André Chervel:

[...] o sistema escolar é detentor de um poder criativo insuficiente valorizado até aqui é que ele desempenha na sociedade um papel o qual não percebeu que era duplo: de fato ele forma, não somente os indivíduos, mas também uma cultura que vem por sua vez penetrar, moldar, modificar a cultura da sociedade global. (CHERVEL, 1990, p. 184)

Dentro do sistema escolar, as cadeiras estudadas também servem como guias para o conhecimento e problematização de determinadas facetas do passado. No caso em foco, com relação ao estudo das Línguas, Souza (1999) informa que, no período de 1912 a 1925, houve uma presença amplamente hegemônica que vinha sendo constituída desde o século XIX. No caso dos estudos de Felte Bezerra, embora sem informações mais detalhadas, notam-se as disciplinas de Latim, Francês, Inglês, Alemão e Português. Já elementos da exposição de vários conteúdos da disciplina de História de Artur Fortes em suas aulas, no Colégio Tobias Barreto, são apontados por Felte Bezerra:

Nas aulas de História, o mestre deixava-se tomar de arrebatamento, empolgado pelo que descrevia... O jovem tenente Bonaparte atravessando a ponte de Arcole. O soldado ofegante até a morte que vinha anunciar a vitória de Maratona. Alexandre mandando colocar Bucefálo à sombra, pois só assim se deixava cavalgar, sem espantar-se. As discutidas figuras de Fouché, Richelieu, Calabar, Feijó. O imprevisível e arroubado Pedro I. A epopeia dos bandeirantes. A sagacidade de Henrique IV, refugiando-se no Louvre para livrar-se da Noite de São Bartolomeu, que o tinha como alvo. A insensatez com que a convenção decaptou Lavoisier com o "a França não precisa de sábios" A imolação de Jenae D’Arc. O comportamento demoníaco dos Médici. O requinte cavalheiresco dos franceses na batalha inicial da $1^{\text {a }}$ Grande Guerra. "Tirez Le premier, messieurs les Anglais".? (BEZERRA, 1981b)

Os escritos de Felte indicam fragmentos de aulas ocorridas há mais de meio século. Referem-se à dinâmica de ensino de Fortes e a alguns dos conteúdos ali possivelmente ensinados. Os conteúdos abarcam desde a Antiguidade com "Alexandre" até a Primeira Guerra Mundial, que aparece justamente no final da descrição do filho de

\footnotetext{
7 Tradução livre: “Atirem primeiro, cavalheiros Ingleses”.
} 
Abdias Bezerra. Vale ressaltar, com base em Freitas (2008), que a citada Guerra não aparece no programa da cadeira de História de 1916 e somente é listada nos programas de 1926.

Elementos da História do Brasil como D. Pedro I, Feijó e Calabar também denotam o que foi ensinado a Felte naquelas aulas de História com Arthur Fortes. Além do mais, cabe destacar o trato com os conteúdos relacionados à História da França, constantemente rememorado por ex-alunos de Fortes. A aproximação com aquele país e as teorias estritamente ligadas à Europa podem ser resultados da formação do sergipano na Escola da Praia Vermelha no Rio de Janeiro.

Com as aulas de Arthur Fortes e outros intelectuais sergipanos, transcorreu a formação do estudante Felte Bezerra no Colégio Tobias Barreto. Seus primeiros anos de educação foram calcados em uma escola uma disciplina rígida, com leituras, aulas durante todo o dia e sendo aluno dos mestres que, anos depois, seriam seus colegas de profissão na Congregação do Atheneu Sergipense.

Felte Bezerra registrou que contou com "mestres de tudo" ao fazer referência Arthur Fortes e Abdias Bezerra; pensamos que esses docentes fizeram o papel do que Sirinelli (2003, p. 246) considera como “despertadores”, por “[...] representaram um fermento para as gerações intelectuais seguintes, exercendo uma influência cultural e mesmo às vezes política". Indubitavelmente, os "mestres de tudo" foram “despertadores" do jovem estudante aqui investigado que frequentou o Colégio Tobias Barreto nas primeiras décadas do século XX.

E assim, terminado o secundário em 1924, sem condições financeiras de seguir para outro estado a fim de cursar o Ensino Superior, Felte Bezerra resolveu cursar Escrituração Mercantil à noite. Entre os anos de 1925 e 1926, trabalhou no Banco de Sergipe e, logo depois, assumiu a gerência do escritório comercial de Heráclito Rocha em uma firma exportadora de sal e outros produtos. Ali, permaneceu até 1929, quando pediu demissão para prestar exame na Faculdade de Medicina da Bahia.

Sobre esse período da sua vida, entre o término do Ensino Secundário e o ingresso no Ensino Superior na Bahia, o contemporâneo Garcia Moreno (1952, p. 3) assim descreve: "Quem o visse, mais tarde, num dos melhores escritórios comerciais da 
província, chefe da contabilidade, reto idôneo eficiente, cercado de louvores e consideração dos meios mercurianos, acredita-lo-ia feito para tais mistérios, abrindo uma exceção na linha tradicional da família de professores". A tal ressalva à "linha tradicional da família de professores" não se cumpriu, pois os diferentes itinerários de Felte Bezerra também perpassaram o magistério.

Antes disso, procurou registrar que sua vida estudantil foi marcada por distinções. "Conclui meus estudos secundários, no mês que fazia 16 anos, tive um curso secundário bem feito, não melhor devido a minha pouca idade" (BEZERRA, 1988). Alguns anos após a conclusão do Ensino Secundário, Felte Bezerra seguiu para a Bahia para cursar o Ensino Superior.

\section{Felte Bezerra: o descontentamento com a formação em Odontologia}

Em 1924, Felte Bezerra, com 16 anos, havia concluído o Curso Secundário no Colégio Tobias Barreto. Desse modo, caso almejasse continuar os estudos teria que deixar Aracaju para cursar o Ensino Superior em outra cidade como o Rio de Janeiro, Salvador ou Recife. Sobre essa fase da vida, Felte escreveu: “Assisti a saída dos colegas de turmas para as Universidades, mas não tinha condições de acompanhá-los. Meu pai sempre foi muito pobre, probo, altamente respeitado mas sem recursos para manter-me fora para estudar" (BEZERRA, 1988, p. 3).

Somente no ano de 1929, após cursar Escrituração Mercantil à noite e trabalhar ao longo do dia durante quatro anos em Aracaju, Felte tomou a decisão de estudar na Bahia. Nesse período, trabalhou por quase um ano no Banco de Sergipe e, logo depois, como gerente de um escritório comercial até o final de 1929. Neste ano, em razão da crise de 1929 e do consequente atraso de salários na empresa, pediu demissão do emprego. Com o trabalho e o acúmulo de certo capital, surgiu a ideia de retomar os estudos. Após conversar com o pai e de receber seu apoio, chegava o momento de viajar para tentar uma vaga na Faculdade de Medicina da Bahia.

Os primeiros dois meses foram de curso preparatório na Capital baiana, depois ocorreu a realização das provas. Com a aprovação, ingressou para os cursos médicos que contemplavam: Medicina, Farmácia, Odontologia e Veterinária, obtendo o primeiro lugar 
em Odontologia com média 8,75 (FELTE, 1988). Conforme Dantas e Nunes (2009), Felte Bezerra queria cursar Medicina, mas devido ao custo oneroso para uma família ampla e de poucas posses, “optou” por cursar Odontologia. Para Suzana Bezerra, filha de Felte, o pai seguiu para a Odontologia:

Para não sacrificar meu avô que era um simples professor. Para mantê-lo na Bahia, tomou emprestado ao montepio do Estado. Embora tenha passado em primeiro lugar no vestibular e mantido durante todo o curso de Odontologia, naquela época não havia bolsa de estudos. O que ele queria mesmo era cursar medicina, mas o curso era mais longo ele achou que sacrificaria demais o pai. Resolveu fazer odontologia. Tanto que seus amigos foram basicamente os colegas de Sergipe que estudavam medicina, à época que cursava odontologia. (BEZERRA, 2015, s/p.)

A vontade de retornar à Bahia para cursar Medicina foi, aos poucos, sendo dissipada pela necessidade de emprego e sustento do jovem que, por essa época, já contava com vinte e cinco anos de idade. Nas terras baianas, cursou Odontologia entre 1930 e 1932, recebendo o diploma de Cirurgião Dentista em 1933.

Em seus escritos, destaca constantemente seus méritos no curso e as decepções com “[...] alguns professores, os mais fracos" (BEZERRA, 1988). Adquiriu livros e lia em francês e inglês com facilidade. Com esse segredo, afirmou levar vantagem sobre seus colegas. Diante desse fato, mais uma vez, ressaltou em suas memórias: "Devo tudo a Abdias e Alcebíades que me ensinaram a ler na língua, sem perder tempo em traduzir" (BEZERRA, 1988, p. 5). Garcia Moreno (1952) apontou alguns aspectos da decepção de Felte com os estudos superiores:

A vossa vida acadêmica foi um curriculum todo riscado de distinções. Todavia ereis, no curso, de certa maneira, um decepcionado. Fostes para aprender e dominar uma especialidade e ouvistes, muitas vezes, dissertações ôcas, palavrosas, numa língua que podia ser "estomatológica" mas que não era, de forma alguma vernácula. Ainda guardo comigo, tão vivo, como se fosse de ontem, um dos vossos comentários cheios de "cólera sagrada" a respeito da ignorância quase traumatizante de um dos vossos colegas de turma, a quem tocava a vez na banca de estudos, de traduzir um capítulo de Anatomia de Testut. $O$ texto começava assim: "Les dents chez l'homme..." Os dentes na casa do homem foi a tradução que nos vos consentiu retornar jamais ao grupo de estudos. (MORENO, 1952, p. 5-6) 
As distinções angariadas por Felte Bezerra fizeram com que ele e mais quatro colegas, os primeiros colocados da turma que colaram o grau em 1933, ganhassem uma "viagem de estudos" para o Rio de Janeiro, “[...] na verdade um passeio de 15 dias" (BEZERRA, 1988, p. 5). Após a colação de grau e a viagem, que lhes possibilitou conhecer a capital do país e a cidade que, décadas depois, iria morar em definitivo, Felte regressou para Sergipe com o diploma de Bacharel em Odontologia.

Ainda sobre seu período de Graduação, Cabral Machado (1998), que poucos anos depois do retorno de Felte a Sergipe, morou na Bahia, escreveu: “É então como outros sergipanos, acadêmico, entre estudos e brincadeiras, pelas pensões de Salvador Travessa dos Aflitos, rua do Bispo. Na pensão Glória, fora colega de Garcia Moreno, Lourival Bonfim, Marques Guimarães e outros em 1932" (MACHADO, 1998, p. 135). Para Suzana Bezerra, as melhores recordações de Felte do período em que estudou na cidade de Salvador foram:

Seus amigos com quem conversava muito e foram contemporâneos quando fez odontologia, que conservou até morrer. Dr. Lourival Bonfim, Dr. José Machado de Souza. Especialmente Dr. Lauro Porto, que saía lá de casa às 2:00 hs. da manhã, conversando até tarde, seus amigos de cátedra no Ateneu Dr. Garcia Moreno. (BEZERRA, 2015, s/p)

O companheiro de pensão, a posteriori de profissão e da vida, Garcia Moreno, escreveu que o Curso Superior na Bahia forneceu a Felte um gosto maior pelo estudo e o animou a seguir a "tradição familiar". Além das distinções recebidas na Faculdade de Odontologia, seu contemporâneo e responsável pelo discurso de recepção de Felte Bezerra na ASL, assim o descreve:

Posso dizer que foi na Bahia que vos conheci. Primeiro, nos encontros fortuitos na Escola Medicina. Depois mais intimamente, na vida comum das pensões. Na casa de ALEXANDRE FREIFER com SILVA RIBEIRO FILHO, PYRES WYNNE, JOSÉ DE FARO e ALFREDO MONTES, até o dia em que $o$ barulhento e ingênuo foot-ball, no sótão da pensão, feriu a sensibilidade sergipana de dona SINHÁ, mobilizou as fúrias libanesas do sr. FREIFER e nos veio a todos o convite irrecorrível de desocupação. Marchámos, então, da travessa dos Aflitos para a rua do Bispo, rumo a velha pensão Glória, onde os pratos que não constavam do cardápio eram extraordinários, conforme prescrevia observações destacadas da 
gerência, e os que constavam eram ordinaríssimos segundo a emenda verdadeira de Adolfo Góes. (MORENO, 1952, p. 5)

Pela exposição, evidenciam-se alguns aspectos do cotidiano do acadêmico na capital baiana: os locais frequentados, amizades, estripulias próprias da vida de universitários, além de desvelar algo tão comum no cotidiano dos estudantes sergipanos em terras do estado vizinho - a vivência nas pensões que conferia uma formação para além dos diplomas de Ensino Superior que ali angariavam.

Segundo o próprio Felte Bezerra, na Faculdade de Odontologia: “Dois ou três professores de valor e o resto de uma mediocridade sem par [...] Minha sorte foi que na pensão de estudante pobre onde morei em Salvador, juntei-me a conterrâneos [...] a maioria era de estudante de medicina e com eles fui aprendendo muitas coisas" (BEZERRA, 1988, p. 6). Felte Bezerra também escreveu acerca do seu trabalho de conclusão de Curso em Odontologia:

\begin{abstract}
Para escrever o meu trabalho de conclusão de curso estudei nos livros de pediatria deles. Meu trabalho intitulado $O$ primeiro dente defendia a tese, então em aberto, e hoje passada em julgado, de que não havia doença específica da dentição, mas um estado de menor resistência em que fica a criança por ocasião do rompimento dos primeiros alvéolos. Fui arguido e deram-me uma distinção pelo inédito do acontecimento, disseram médicos e dentistas que julgaram meu trabalho. (BEZERRA, 1988, p. 6)
\end{abstract}

Estudar nos livros "deles" denota a separação existente entre os alunos de Medicina e os demais cursos que a Faculdade agregava. Outro ponto ressaltado é a participação de médicos e dentistas na banca de avaliação do trabalho final, o que denota um corpo docente misto na formação dos odontólogos daquela instituição. Ainda sobre as cadeiras e os professores da Faculdade, somente algumas pistas, como a referência de Felte Bezerra a uma aula prática, descrita a seguir:

Na cadeira de química, entra o assistente na sala onde fazíamos a prática de fisiologia querendo me identificar. Apresentei-me meio assustado como um bom calouro. Ele me olhou de alto a baixo e disse: 'Você tirou 10,0 com Euvaldo (prof. Euvaldo Diniz Gonçalves). Olhe, é raríssimo 
alguém obter essa nota com Euvaldo, causa especie' e foi embora... (BEZERRA, 1988, p. 5)

Ao cotejar os escritos com o livro "Memórias Históricas da Faculdade de Medicina entre os anos de 1925 a 1941", organizado pela memorialista Cristina Fortuna (2014) e a Reforma João Luiz Alves, conhecida como Reforma Rocha Vaz (1925), nota-se que as cadeiras tanto de Química quanto de Fisiologia compunham o quadro dos conhecimentos do primeiro ano do curso de Odontologia, o que corrobora com a descrição, quando ele se refere ao "calouro", como também à cadeira de Química Metalúrgica sob a responsabilidade do professor Euvaldo Diniz Gonçalves. Por meio das memórias da instituição e da Reforma Rocha Vaz, foi possível construir o Quadro 2:

Quadro 2 - Itinerários do discente Felte Bezerra no curso de Odontologia da Faculdade de Medicina da Bahia (1930-1932)

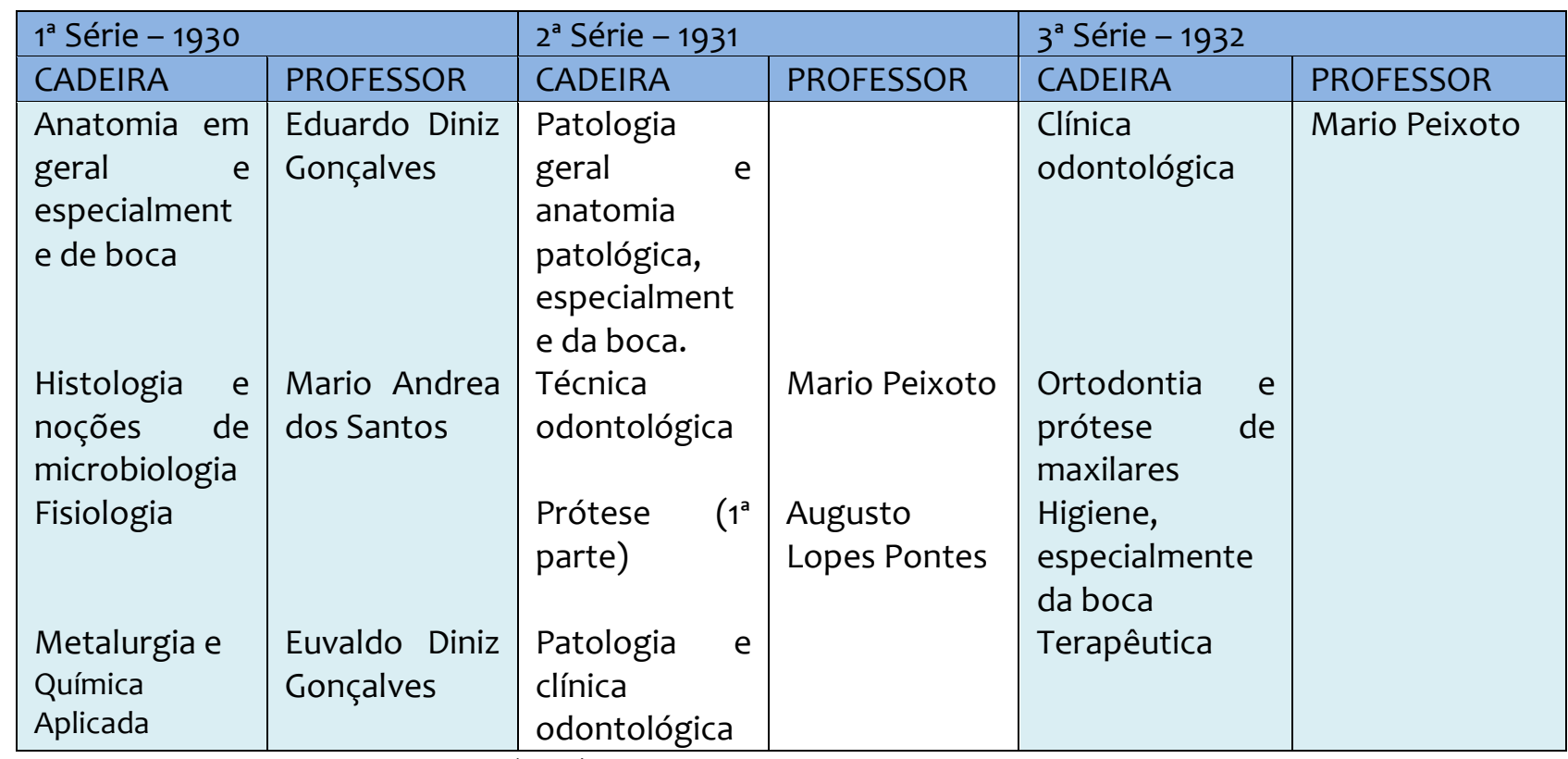

Fonte: Quadro extraído de Oliveira (2015).

Os professores do curso de Odontologia, que tinham a formação como Cirurgiões Dentistas, não compunham o cargo de catedráticos da Faculdade de Medicina. Consoante a Reforma Rocha Vaz, o grau mais elevado de Docente na instituição era de Professor Privativo. Tal fato já denota as distinções e as disputas existentes no espaço da 
instituição, elementos que podem ter refletido na decepção de Felte com o Curso, aliado à sua própria vontade frustrada de cursar Medicina.

A partir dos dados extraídos da "Galeria dos Professores Encantados da FMB", disponibilizados no site da Universidade Federal da Bahia, foi possível tecer algumas considerações sobre os professores de Felte Bezerra. Dos médicos que trabalharam no Curso de Odontologia, constam: Euvaldo Diniz Gonçalves, livre docente de Química Geral da FAMEB e Química Metalúrgica no Curso de Odontologia.

De acordo com o ex-aluno Ruy Santos, ele tinha conhecimento, mas não sabia ensinar, não era um didata. Já Eduardo Diniz Gonçalves, era conhecido como o “Biriba”, sinônimo de reprovação e terror para os calouros, professor catedrático de Anatomia Médica Cirúrgica e Operações da Faculdade de Medicina e docente de Anatomia no Curso de Odontologia. Por fim, Mário Andreas Peixoto, Professor catedrático de Anatomia e Fisiologia Patológica, desde 1916, a partir da Reforma Rocha Vaz, em 1925, passou a reger a cátedra de Histologia e Microbiologia para o curso de Odontologia.

Dos professores específicos do curso de Odontologia, a Escola Anexa, foram localizados: Mário Peixoto e Augusto Lopes Pontes ${ }^{8}$. Mario Peixoto possuía um vasto currículo contando inclusive com uma pós-graduação na School of Dentistry of Philadelphia, entre outros cursos realizados nos Estados Unidos da América nas primeiras décadas do século XX. Chegou ao ápice da carreira na Escola Anexa de Odontologia com o grau de professor privativo em 1927 (FORTUNA, 2014). Além desses, sabe-se que Luís Antônio de Aguiar, dentista e médico, lecionou por décadas no curso de Odontologia, inclusive no período de graduação de Felte Bezerra, mas não conseguimos identificar suas cadeiras de atuação nessa época.

Com esses e outros docentes, com conhecimentos teóricos e práticos, formou-se o cirurgião dentista Felte Bezerra na Bahia. Além da sala de aula, nas pensões e estudos com colegas, o filho do professor Abdias leu, estudou, decepcionou-se; mesmo assim, conseguiu uma distinção na sua fase de acadêmico a ponto de ser premiado com uma viagem à capital do país após a formatura. Com o diploma nas mãos, chegou a hora de

\footnotetext{
${ }^{8}$ Não conseguimos outras informações acerca da formação e atuação desse professor; nas pesquisas constantes, localizamos somente a rua da cidade de Salvador que leva esse nome, bem como a referência por ser pai de Maria Rita de Souza Brito Lopes Pontes, a Irmã Dulce.
} 
voltar à terra natal, montar o consultório e começar a atender seus pacientes; todavia, os caminhos do Magistério mudaram o percurso do então recém-formado dentista.

Sirinelli (1994, p. 13) questiona como necessário analisar o "Étude d'itinéraries a partir d'um terreau commun?" 9 . Na formação de Felte Bezerra, a instituição de ensino secundário, Tobias Barreto em Aracaju, e a Escola Anexa de Odontologia, constituíam-se como "terreno comum" na formação de jovens brasileiros, além disso, podem ser entendidas também como "[...] fornecedoras de elites culturais” (SIRINELLI, 1998, p. 16).

Dos seus itinerários como aluno, emergem nomes de professores que contribuíram na sua formação. São docentes formados no final do século XIX e início do século XX, rememorados pelo domínio do assunto, paixão pelo humanismo, riqueza de detalhes na exposição de conteúdos, ou mesmo, aspectos negativos e decepcionantes de algum trajeto do período formativo. Lembranças de alguns professores contribuíram para aproximar esse sujeito da profissão docente e mesmo do ingresso no Magistério. Indubitavelmente, os "mestres de tudo" foram "despertadores" do jovem estudante, aqui investigado, que frequentou as aulas de diferentes instituições educacionais na primeira metade do século XX.

Diante do foco da presente investigação, por meio da análise das fontes, relevouse que as práticas escolares dos seus professores, somadas ao universo cultural no qual Felte Bezerra estava inserido, contando com contribuições do ambiente familiar, com as amizades dentro e fora da sala de aula, as viagens e as mudanças para estudar, constituem-se como elementos que reiteram o significado da instituição educacional na sociedade, assim como reafirmam a importância dos estudos dos itinerários formativos para a compreensão do intelectual. Os seus percursos escolares desvelaram instituições educacionais, docentes, disciplinas e seus conteúdos, elementos cruciais para o entendimento da História da Educação Brasileira na primeira metade do século XX.

\footnotetext{
${ }^{9}$ Tradução livre: “O estudo dos itinerários a partir de um terreno comum?”.
} 


\section{Referências}

ALVES, Eva Maria Siqueira. O Atheneu Sergipense: uma Casa de Educação Literária examinada segundo os Planos de Estudos (1870/1908). 2005. 318 p. Tese (Doutorado em Educação). Programa de Estudos Pós-Graduados em Educação: História, Política e Sociedade, PUC/SP. 2005.

BARROSO, Cristina de Almeida Valença Cunha. Reformas educacionais e a pedagogia moderna: mudanças no pensar e fazer pedagógico da Escola Normal (1911-1931). 2011. 263 p. Tese (Doutorado em Educação). Programa de Pós-Graduação em Educação da Universidade Federal da Bahia (UFBA). Salvador/BA, 2011.

BEZERRA, Felte. Abdias Bezerra: traços psicológicos de um educador. Aracaju: (s.n.t.), 1947.

BEZERRA, Felte. Artur Fortes. Gazeta de Sergipe. Aracaju/SE. 1 a 4 de março. de 1981a. p. 3. Hemeroteca do IHGSE.

BEZERRA, Felte. Evocações. Gazeta de Sergipe. Aracaju/SE. 19 e 20 de Agosto de 1981b. Hemeroteca do IHGSE.

BEZERRA, Felte. Notícias sobre minha vida (anotações autobiográficas) Cópia digital no MUHSE/UFS, Aracaju/SE. 1988.

BEZERRA, Suzana Resende. Filha de Felte Bezerra. Questionário respondido ao autor via e-mail em 16 de julho de 2015. Rio de Janeiro/RJ, 2015.

BONTEMPI JÚNIOR, Bruno. Os significados da vida estudantil e da escola nos memoriais dos candidatos à docência na FEUSP (1988-2005). In: MORAES, Dislane Zerbinatti. LUGLI, Rosario Silvana Genta. Docência, pesquisa e aprendizagem: (auto) biografias como espaços de formação/investigação. São Paulo: Cultura Acadêmica, 2010. p. 165-178.

BRASIL. Reforma João Luiz Alves (conhecida por Lei Rocha Vaz). Decreto $n^{\circ} 16.782-13$ de Janeiro de 1925. História da Educação, ASPHE/FaE/UFPel, Pelotas, v. 13, n. 28 p. 253-290, maio/ago. 2009.Disponível em: http//fae.ufpel.edu.br/asphe. Acesso em 18 de outubro de 2014.

BRASIL. Reforma Carlos Maximiliano. Decreto n 11.530, de 18 de Março de 1915.

Reorganiza o ensino secundario e o superior na Republica.

Disponível em: <http://www2.camara.leg.br/legin/fed/decret/1910-1919/decreto-11530-18marco-1915-522019-republicacao-97760-pe.html>. Acesso em: 18 de outubro de 2014.

CABRAL, Mario. Folclore infantil na cidade de Aracaju. Revista de Aracaju. Ano 4, n. 4,. p. 183-234, 1951.

CARVALHO, José Murilo de. Euclides da Cunha e o Exército. Revista Brasileira da

Academia Brasileira de Letras. Rio de Janeiro. Prosa 3, 2010; p. 133-158. Disponível em: 
<http://academia.org.br/abl/media/REVISTA\%20BRASILEIRA\%2063-prosa-03.pdf >. Acesso em: 12 de agosto de 2012 .

CHERVEL, André. História das disciplinas escolares: reflexões sobre um campo de pesquisa. Teoria \& Educação. Porto Alegre/RS. n. 2, p. 177-229, 1990.

DANTAS, Beatriz Góis; NUNES, Verônica Maria Meneses. Destinatário - Felte Bezerra: cartas a um antropólogo sergipano $1947-59$ e 1973-85. São Cristóvão: Editora UFS, 2009.

DANTAS, Ibarê. História de Sergipe, República (1889-2000). Rio de Janeiro: Tempo Brasileiro, 2004.

DÓREA, Epifânio. Aracaju de outrora. Revista de Aracaju. Aracaju. Ano V., p. 109-117, 1954.

FORTUNA, Cristina Maria Mascarenhas. Memória histórica da Faculdade de Medicina da Bahia (1925-1941). Salvador: (s.n.t.). 2013-2014.

FREITAS, Itamar. A pedagogia histórica de Jonathas Serrano: uma teoria para o ensino de história para a escola secundária brasileira (1913-1935). São Cristóvão: Editora UFS; Aracaju: Oviêdo Teixeira, 2008.

GONTIJO, Rebeca. O intelectual como símbolo da brasilidade: o caso Capistrano de Abreu. In: ABREU, Marta; SOIHET, Rachel; GONTIJO, Rebeca (Orgs.). Cultura política e leituras do passado: historiografia e ensino de história. Rio de Janeiro: Civilização Brasileira: 2007. p. 309-328.

GUARANÁ, Armindo. Dicionário biobibliográfico sergipano. Rio de Janeiro: Pongetti. 1925.

LOUREIRO, Kátia Afonso S. A trajetória urbana de Aracaju em tempo de interferir. Aracaju, Instituto de Economia e Pesquisa - INEP, 1983.

MACHADO, Manoel Cabral. Brava gente sergipana e outros bravos. UFS: Aracaju/SE, 1998.

MANGUEIRA, Francisco Igor de Oliveira. Colegio Tobias Barreto: escola ou quartel? (19091946). 2003. 151 p. Dissertação (Mestrado em Educação) - Programa de Pós-Graduação em Educação da Universidade Federal de Sergipe (UFS). São Cristóvão/SE, 2003.

MATOS, Mariângela Silva de et al. Faculdade de Odontologia - Histórico. In: TOUTAIN, Lídia Maria Brandão. SILVA, Rubens Ribeiro Gonçalves (Orgs.). UFBA: do século XIX ao século XXI/ Universidade Federal da Bahia. Instituto de Ciência da Informação. Salvador: EDUFBA, 2010. p. 497-510.

MORENO, João Batista Perez Garcia. Saudação ao Dr. Felte Bezerra. Revista da Academia Sergipana de Letras. Aracaju: Imprensa Oficial. n 16, p. 3-15, 1952. 
OLIVEIRA, João Paulo Gama. Caminhos cruzados: itinerários de pioneiros professores do ensino superior em Sergipe (1915-1954). 319 p. Tese (Doutorado em Educação) - Programa de Pós-Graduação em Educação. Universidade Federal de Sergipe, São Cristóvão - SE, 2015.

PESAVENTO, Sandra Jatahy (Org.) História e História Cultural. 2 ed. Belo Horizonte: Autêntica, 2005.

SILVEIRA, Joel. Na fogueira: memórias. Rio de Janeiro: Mauad. 1998.

SIRINELLI, Jean-François. Le hasard ou la necessité: une histoire en chantier: L'histoire des intelectuells. Vingtième Siècle: Revue d'Histoire. v. 9, n. 1. jan./maio, 1986, p. 97-108.

SIRINELLI, Jean-François. Génération intelellectuell: Khâgneux et Normaliens dans l'êntre-deux-guerres. Presses Universitaire de France, Paris: 1994. 